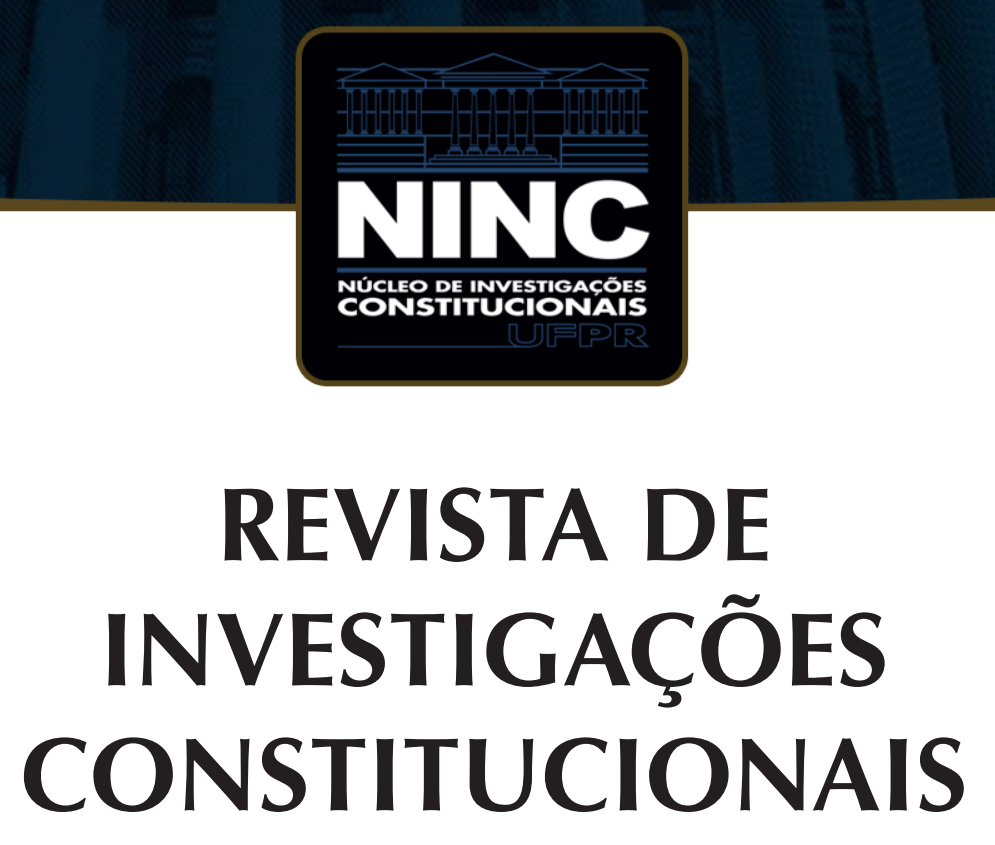

JOURNAL OF CONSTITUTIONAL RESEARCH

vol. 6 | n. 2 | maio/agosto 2019 | ISSN 2359-5639 | Periodicidade quadrimestral Curitiba | Núcleo de Investigações Constitucionais da UFPR | www.ninc.com.br 


\title{
Repensando o Direito Constitucional Comparado no Brasil
}

\section{Rethinking Comparative Constitutional Law in Brazil}

\author{
EMILIO PELUSO NEDER MEYER ${ }^{\text {I, * }}$
}

'Universidade Federal de Minas Gerais (Brasil) emiliopeluso@gmail.com https://orcid.org/0000-0002-7500-0705

Recebido/Received: 18.02 .2019 / February $18^{\text {th }}, 2019$ Aprovado/Approved: 30.10 .2019 / October 30 ${ }^{\text {th }}, 2019$

Resumo

O artigo reconstrói alguns dos avanços no campo do Direito Constitucional Comparado. Recorrendo à literatura recente, ele começa com uma definição do estado da arte da temática no Brasil. Segue-se uma advertência contra o predomínio de perspectivas que privilegiem o norte global. A relação entre comparativismo e judicialização indica as razões do renascimento da disciplina por meio de uma atividade mais proeminente de juízes e tribunais. Temas de perfil metodológico, como a diferença entre análise small- $N$ e large- $N$, metáforas adequadas, segmentação comparada e a reivindicação de transdisplinariedade, são discutidos com vistas a redirecionar o debate. O método de revisão da literatura é alargado com uma verificação de dois exemplos de uso equivocado do comparativismo: o voto da Ministra Rosa Weber no Habeas Corpus 152.752 e a discussão sobre atiradores de elite. Os resultados de pesquisa indicam a necessidade de repensar o Direito Constitucional Comparado da forma como é trabalhado no Brasil.

Palavras-chave: Direito Constitucional Comparado; comparativismo; transdisciplinariedade; judicialização; Supremo Tribunal Federal.

\section{Abstract}

The article reconstructs some of the improvements in the field of Comparative Constitutional Law. Using recent literature, it starts with a definition of the state of art of the subject in Brazil. A warning against the predominance of perspectives that privilege the global north. The relationship between comparativism and judicialization indicates the reasons of the rebirth of the subject through a stronger activity of judges and tribunals. Themes with methodological approach, like the difference between small- $N$ and large- $N$ analyses, adequate metaphors, comparative segmentation and the call for transdisciplinarity, are discussed with the aim of driving the debate. The literature review method is enriched with the checking of two examples of mistaken comparativism using: Justice Rosa Weber opinion in the Habeas Corpus 152.752 and the debate on snipers. The research results indicate the necessity of rethinking the way Comparative Constitutional Law is used in Brazil.

Keywords: Comparative Constitutional Law; comparativism; transdisciplinarity; judicialization; Supreme Court.

Como citar esse artigo/How to cite this article: MEYER, Emilio Peluso Neder. Repensando o Direito Constitucional Comparado no Brasil. Revista de Investigações Constitucionais, Curitiba, vol. 6, n. 2, p. 479-502, maio/ago. 2019. DOI: 10.5380/rinc.v6i2.65009.

" Professor Adjunto de Direito Constitucional da Faculdade de Direito da Universidade Federal de Minas Gerais (Belo Horizonte-MG, Brasil). Mestre e Doutor em Direito pela UFMG. Visiting Researcher no King's College Brazil Institute (2014-2015). Coordenador do Centro de Estudos sobre Justiça de Transição da UFMG. Fellow no King's College Transnational Law Summer Institute (2016). Pesquisador em Produtividade do CNPQ (Nível 2). E-mail: emiliopeluso@gmail.com. 


\section{SUMÁRIO}

1. Introdução; 2. Uma definição do estado da arte do Direito Constitucional Comparado; 3. Contra o imperialismo no Direito Comparado; 4. Comparativismo e judicialização; 5. Empréstimos constitucionais, transplantes jurídicos, migração de ideias constitucionais: qual metáfora? 6. Quem importa no Direito Constitucional Comparado? 7. Transdisciplinariedade nos estudos constitucionais comparados; 8. Análises small-N e large-N; 9. Usos equivocados do Direito Comparado no Brasil; 10. Conclusões; 11. Referências.

\section{INTRODUÇÃO}

O renascimento do Direito Constitucional Comparado tem sido objeto de ampla discussão. Países acostumados a se autorreferenciar em termos de constitucionalismo, como os Estados Unidos, têm dirigido boa parte de sua atenção para o que acontece em outras jurisdições. Esse movimento remonta a meados dos anos 1990. Hirschl narra as dificuldades iniciais apresentadas por obstáculos como "internet discada" (dial-up internet access) para se ter acesso a bancos de dados jurisprudenciais de cortes estrangeiras mesmo em universidades como Yale ${ }^{1}$, para além dos enormes estoques de coleções antigas que traziam material de julgados. Imagine-se a dificuldade em estruturas universitárias do sul global. A situação é hoje contrastada com a construção cada vez mais ampla de bancos de dados sobre decisões judiciais por parte de inúmeras cortes, mas também de fontes bibliográficas constitucionais vastas, como os projetos Constitute $^{2}$ do Comparative Constitutions Project ${ }^{3}$, World Constitutions Illustrated ${ }^{4}$, mantido pela gigantesca base de dados Hein Online, além de inúmeras publicações no campo de conhecimento. 5

Ao lado da expansão instrumental que a internet permitiu, verifica-se um crescente e robusto interesse em outras jurisdições impulsionado não só por objetivos acadêmicos, mas também por demandas de tribunais (que, não raro, usam mal o Direito Constitucional Comparado) e mesmo de participantes de processos constituintes. Ao

\footnotetext{
1 HIRSCHL, Ran. Comparative Matters: The Renaissance of Comparative Constitutional Law. Oxford: Oxford University Press, 2014, p. 1.

2 Disponível em: <https://www.constituteproject.org>. Acesso em: 9 maio 2017.

3 Coordenado por Zachary Elkins, Tom Ginsburg e James Melton. Disponível em: <http://comparativeconstitutionsproject.org>. Acesso em: 9 maio 2017.

4 Disponível em: <http://heinonline.org/HOL/Index?collection=cow\&set_as_cursor=clear $>$. Acesso em: 9 maio 2017.

5 Apenas para ficar em dois exemplos mais ambiciosos, cf. a Max Planck Encyclopedia of Comparative Constitutional Law (Disponível em: <http://oxcon.ouplaw.com/page/590> Acesso em: 9 maio 2017) e a coleção Constitutional Sytems of the World, da editora Hart Publishing, que publica volumes sobre análises contextuais de diversas ordens constitucionais como Israel, Chile, Singapura, Espanha, África do Sul, entre muitos outras (Disponível em: <http://www.bloomsburyprofessional.com/series/constitutional-systems-of-the-world/>. Acesso em: 9 mai 2017), sendo editada pelos Professores Peter Leyland, Andrew Harding, Benjamin Berger, Rosalind Dixon e Heinz Klug.
} 
mesmo tempo, pouco se tem avançado em proposições metodológicas mais robustas. No caso brasileiro, a questão é agravada também pela ausência de interesse por regiões e países do sul global: por que não investir em estudos de sistemas constitucionais mais parecidos com o brasileiro (por exemplo, México), ao invés de olhar apenas para os Estados Unidos e a Europa ocidental? É curioso que este não é um problema apenas nosso. Hirschl menciona que a Suprema Corte de Israel ${ }^{6}$, talvez em busca do "título" de democracia liberal ocidental, privilegia a referência a casos decididos nos Estados Unidos, no Reino Unido, na Alemanha e no Canadá. Prejudica-se, senão anula-se, contextos de divergência étnica similar ao de Israel, como Índia, Turquia ou Malásia.

Desse modo, o artigo que se segue visa apontar algumas questões metodológicas importantes. O objetivo geral é o de, ainda que à guisa de considerações mais gerais, provocar o pesquisador, o acadêmico, o propositor de políticas públicas, o promotor e o juiz para que compreenda a necessidade de repensar o significado do Direito Constitucional Comparado. Para tanto, recorreremos, com o uso de um método exploratório, aos principais referenciais teóricos que tanto introduzem o estado da arte quanto avançam na tentativa de muda-lo. A metodologia também se socorre de dois exemplos de usos equivocados do Direito Constitucional Comparado, via uma análise jurisdicional e uma análise acadêmica. Destaque-se que não se supõe um amplo hiato entre esses campos, apesar de tribunais, especialmente no Brasil, assim indicarem. Os resultados de pesquisa apontam que há, de um lado, uma verdadeira inquietação que tanto move a academia a olhar mais além do chamado norte global e das antigas referências tidas como canônicas, quanto a de adequadamente indagar qual é o modo adequado de enxergar o campo.

\section{UMA DEFINIÇÃO DO ESTADO DA ARTE DO DIREITO CONSTITU- CIONAL COMPARADO}

Uma marcante reconstrução histórica do Direito Constitucional Comparado é feita no recente trabalho de Ran Hirschl. ${ }^{7}$ Ele retoma três obras fundamentais produzidas no campo do Direito Público nos séculos XVI, XVII e XVIII: Jean Bodin e seus "Os seis livros da república" (1576); Jon Selden e seu "De jure naturali et gentium juxta desciplinam ebraorum" (1640); e, Montesquieu, tanto em "Cartas persas" (1721) quanto em "O espírito das leis" (1748). Mais recentemente, seria possível observar o predomínio de uma quase fusão entre comparativismo político e comparativismo governamental no

\footnotetext{
6 HIRSCHL, Ran. Comparative Matters: The Renaissance of Comparative Constitutional Law. Oxford: Oxford University Press, 2014, p. 9.

7 HIRSCHL, Ran. Comparative Matters: The Renaissance of Comparative Constitutional Law. Oxford: Oxford University Press, 2014, p. 112 e ss.
} 
início do século XX. ${ }^{8}$ É o que seria possível depreender de Georg Jellinek, em “The Declaration of the Rights of Man and of Citizens: A Contribution to Modern Constitutional History" (1895), e de James Bryce, em "The American Commonwealth" (1888).

Avançando sobre o século XX, o "Derecho constitucional comparado", de Manuel García-Pelayo, ${ }^{9}$ publicado pela primeira vez em 1950, divide o empreendimento comparativo em uma primeira parte, dedicada a instituições e institutos que podem ser colhidos de diversas ordens constitucionais (inclusive propondo-se uma teoria da constituição), e uma segunda parte, em sistemas constitucionais específicos que são mais detidamente analisados: Reino Unido, Estados Unidos, França, Suíça e União Soviética. Note-se a ênfase no ocidente, aparecendo a União Soviética mais como um inevitável caso de comparação a contrario sensu. De qualquer forma, o espanhol que lutara na Guerra Civil daquele país e viria a presidir o Tribunal Constitucional espanhol, apesar de seu conhecimento também em ciência política, não deixa de enfatizar a perspectiva do jurista: o Direito Constitucional Comparado teria como “(...) misión el estudio teórico de las normas jurídico-constitucionales positivas (pero no necesariamente vigentes) de varios Estados, preocupándose de destacar las singularidades y los contrastes entre ellos o entre grupos de ellos".10

Os anos 1960 e 1970 marcariam uma mudança de interesse, dirigida a definir os termos comparados de uma engenharia ou desenho constitucional. Em uma parte significativa dos casos, isto envolveria aprofundar no conhecimento comparado de forma a permitir sólidas transições de situações de conflito ou de regimes autoritários para regimes democráticos. ${ }^{11} \mathrm{E}$ aqui ganharam proeminência os trabalhos de autores muitos mais vinculados à Ciência Política, como Arend Liphart, Juan Linz e Alfred Stepan. Mais recentemente, estudos sobre as relações entre ordens domésticas, internacionais e transnacionais vão também depender de avanços no campo da Sociologia (veja-se, por exemplo, a influência de Niklas Luhmann ou de Günther Teubner no trabalho de Marcelo Neves). De modo semelhante, mesmo debates sobre legitimidade ou a relação entre direito e democracia redimensionaram o significado do Direito Constitucional Comparado e sua relação com a Filosofia Política. ${ }^{12}$ Mesmo para analisar o papel de interesses

\footnotetext{
8 HIRSCHL, Ran. Comparative Matters: The Renaissance of Comparative Constitutional Law. Oxford: Oxford University Press, 2014, p. 157.

9 GARCÍA-PELAYO, Manuel. Derecho constitucional comparado. Madri: Alianza Universidad Textos, 1993.

10 GARCÍA-PELAYO, Manuel. Derecho constitucional comparado. Madri: Alianza Universidad Textos, 1993, p. 20.

11 Para uma discussão sobre constitucionalismo transicional, ver MEYER, Emílio Peluso Neder. Judges and Courts Destabilizing Constitutionalism: The Brazilian Judiciary Branch's Political and Authoritarian Character. German Law Journal, v. 19, p. 727-768, 2018. p. 755; e, em um sentido diverso, mais próximo de uma leitura de ponderação de valores constitucionais, BERNAL-PULIDO, Carlos. Transitional Justice within the Framework of a Permanent Constitution: The Case Study of the Legal Framework for Peace in Colombia. Cambridge J. Int'l \& Comp. L., Cambridge, v. 3, n. 4, p. 1136-1163. 2014, p. 1.136.

12 Pense-se, no caso brasileiro, na produção científica de autores como Lênio Streck (STRECK, Lênio. Jurisdição Constitucional. $5^{\mathrm{a}}$ ed. Rio de Janeiro: Forense, 2018) ou Cattoni de Oliveira (CATTONI DE OLIVEIRA,
} 
de setores específicos da arena política no desenho constitucional demandaram investigações para além do olhar do jurista, como fizeram o próprio Hirschl e Tom Ginsburg. ${ }^{13}$

Nas décadas de 1980 e 1990, algumas obras tornar-se-iam referências, ao menos em países de civil law (ainda que se deva ter cautela com a pertinência atual dessa distinção). Curiosamente, algumas delas permaneceram com um olhar atento à organização, ainda que não assumissem a perspectiva de uma maior transdisciplinariedade. A "Introduzione al diritto costituzionale comparato", de Biscaretti de Ruffia, publicada originalmente em 1988, foca excessivamente no dualismo forma de Estado e forma de governo, para, entretanto, explicitamente assumir um ponto de vista jurídico, vez que o Direito Constitucional comparado seria uma ciência jurídica. O autor não deixa, contudo, de assinalar a preferência de autores de common law pela ausência de cisão do campo do Direito Constitucional Comparado com o comparative government. ${ }^{14}$

No caso brasileiro, obras exclusivamente dedicadas ao Direito Constitucional Comparado e preocupadas com questões metodológicas são encontradas com menor facilidade. Ricardo Malheiros Fiuza procurou realizar um estudo mais centrado no Poder Judiciário (mas não exclusivamente), ${ }^{15}$ sem estabelecer bases rigorosas para a escoIha dos sistemas constitucionais. Há elementos do constitucionalismo de Luxemburgo e do Timor-Leste, mas sem uma clara determinação de como trata-los e o que os une e os separa. Ivo Dantas buscou expor o problema da ausência de preocupação com uma "epistemologia" do Direito Constitucional Comparado no Brasil, não sem destacar que discussões prévias sobre o status do Direito Comparado estiveram presentes, mas de modo esparso. ${ }^{16}$

Trabalhos mais recentes procuraram explorar os diversos caminhos seguidos após as mudanças no Direito Constitucional Comparado fora do Brasil. Alonso Freire discutiu critérios de comparabilidade no campo da interpretação judicial voluntária de direitos fundamentais. ${ }^{17}$ De forma mais próxima à deste artigo, Ribas e Dutra trataram do renascimento do Direito Constitucional Comparado em um caminho próximo ao de Hirschl, propondo balizas para o que ele chama de "Estudos Constitucionais

Marcelo Andrade. Contribuições para uma Teoria Crítica da Constituição. Belo Horizonte: Arraes Editores, 2017).

13 HIRSCHL, Ran. Towards Juristocracy: The Origins and Consequences of the New Constitutionalism. New Haven: Harvard University Press, 2004; GINSBURG, Tom. Judicial Review in New Democracies: Constitutional Courts in Asian Cases. Cambridge: Cambridge University Press, 2003.

14 BISCARETTI DE RUFFİA, Paolo. Introducción al derecho constitucional comparado: las "formas de Estado" y las "formas de gobierno". Cidade do México: Fondo de Cultura Económica, 1996, p. 84.

15 FIUZA, Ricardo Arnaldo Malheiros. Direito Constitucional Comparado. 4a ed. Belo Horizonte: Del Rey, 2004.

16 DANTAS, Ivo. Novo direito constitucional comparado. Curitiba: Juruá, 2010, p. 43.

17 FREIRE, Alonso. Interpretação constitucional comparativa: aproximação crítica e arcabouço metodológico. Revista Publicum, n. 2, p. 45-73, 2016. 
Comparados". ${ }^{18}$ Ainda assim, sobram questões urgentes em termos de comparativismo no Brasil.

\section{CONTRA O IMPERIALISMO NO DIREITO COMPARADO}

Uma importante advertência inicial deve guiar qualquer empreendimento de Direito Constitucional Comparado ou o que aqui chamaríamos de um constitucionalismo comparado. Esta advertência está fundada em uma contraposição a um certo tipo de imperialismo que acompanha a estrutura do constitucionalismo que vem, há pelo menos três séculos, tentando se consolidar globalmente. Como destaca James Tully, ${ }^{19}$ ao menos três formas de ação tornaram a "democracia constitucional" ocidental e de perfil estadunidense/europeu parte de um "direito imperial" (imperial right), abrangente de um "direito" dos Estados europeus e suas empresas de participar livremente do mercado de sociedades não europeias e de dois deveres correlatos: o dos Estado europeus de "civilizar" outras sociedades e o de estas sociedades de hospedar práticas europeias.

Por três métodos o "direito imperial" se implementou no último milênio. O primeiro deles consistia o assentamento de colônias europeias nas Américas, na Austrália e na Nova Zelândia. O segundo método partiu de uma "imperialização" via governo colonial indireto, reorganizando governos locais, "civilizando" e ocidentalizando elites locais, dividindo oposições etc. O terceiro método aceita um certo grau de autonomia governamental local desde que sob uma zona de influência ou hegemonia, impondo formas políticas e jurídicas específicas para atender ao livre comércio objetivado por norte-americanos e europeus. A base de projetos como esses é uma palavra bastante recorrente no vocabulário jurídico brasileiro: "civilização". O alcance de um padrão de civilização deve ser o objetivo de Estados que não compartilham os aspectos centrais do constitucionalismo como estabelecido no final do século XIX na Europa e nos Estados Unidos: cabe a esses países conduzir o "dever de civilizar".20

18 DUTRA, Deo Campos; VIEIRA, José Ribas. "O Direito Constitucional Comparado entre Renascimento e Consolidação". Sequência, Florianópolis n. 76, p. 69-94. 2017.

19 TULLY, James. The Imperialism of Modern Constitutional Democracy. In: LOUGHLIN, Martin; WALKER, Neil (orgs). The Paradox of Constitutionalism: Constituent Power and Constitutional Form. Oxford: Oxford University Press, 2007, p. 328.

20 "Como recurso resultante, ricas petrotiranias, ditaduras complacentes com condições péssimas de trabalho em indústrias de roupas e dependências regionais estrategicamente importantes permanecem como 'Estados falidos' instáveis, sendo um resultado direto de sua continua sujeição à manipulação informal imperial: as elites dependentes são constrangidas por sua dependência para suprimir as aspirações democráticas do povo de controle seus próprios recursos e condições de trabalho; pessoas são levadas à violência para autodefesa; isto é chamado de falha e terrorismo; e - como Locke previu - a intervenção é a consequência". Tradução livre de: "The resulting resource rich petrotyrannies, sweatshop dictatorships, and strategically important regional dependencies remain unstable 'failed states' as a direct result of their continuing subjection to informal imperial manipulation: the dependent elites are constrained by their dependency to suppress the democratic aspirations of their people to control their own resources and work conditions; the people are driven to violence in 
Em uma perspectiva crítica próxima daquela de Tully, Pierre Legrand apresenta duas grandes correntes do direito comparado atual: ${ }^{21}$ a) uma tradicional, que ele identifica com o positivismo científico, ainda tributária da relação sujeito/objeto e visando cumprir o objetivo de isolar um objeto de questões culturais e históricas que podem cerca-lo; b) uma corrente mais viva, preocupada com o estudo contextual de normas jurídicas, aberta à atividade interpretativa e ao engajamento transdisciplinar. O direito comparado deveria se aproximar do segundo empreendimento: é isto que possibilitaria que, ao lidar com o estrangeiro e o não familiar, o "comparativismo" suspendesse a normalidade autocentrada e satisfeita consigo mesma. Mais do que isso, ele poderia promover uma prática de reposicionar o jurista perante o mundo e a história.

Para enfrentar o positivismo filosófico que assola o "comparativismo", Legrand sugere que dois processos sejam empreendidos cumulativamente: "enculturação" (enculturation) e "interpretação".22 Conhecer e confrontar as diversas interpretações que se colocam sobre um determinado texto legal demonstra que a tarefa do "comparativismo" é muito mais complexa do que se imagina e demanda muito mais do que opor estruturas vazias de conteúdo. Ao traçar um paralelo com a teoria literária comparada, Sherally Munshi irá destacar que não é a justaposição que define o Direito Comparado, mas uma orientação que, além de intelectual, é ética. ${ }^{23}$ Isto pode revelar a amplitude da tarefa comparativa que, talvez, muito mais do que ser um ramo didático isolado, pode demandar que todo estudo seja comparativo. Nos Estados Unidos, a orientação ainda permanecerá eurocêntrica e é contra isto que se deve lutar. ${ }^{24}$

self-defence; this is called failure and terrorism; and-as Locke predicted-intervention follows" (TULLY, James. The Imperialism of Modern Constitutional Democracy. In: LOUGHLIN, Martin; WALKER, Neil (orgs). The Paradox of Constitutionalism: Constituent Power and Constitutional Form. Oxford: Oxford University Press, 2007, p. 333).

21 LEGRAND, Pierre. Jameses at Play: A Tractation on the Comparison of Laws. The American Journal of Comparative Law, Oxford, v. 65, p. 1-132. 2017, p. 2.

22 LEGRAND, Pierre. Jameses at Play: A Tractation on the Comparison of Laws. The American Journal of Comparative Law, Oxford, v. 65, p. 1-132, 2017, p. 21.

23 MUNSHI, Sherally. Comparative law and decolonizing critique. American Journal of Comparative Law, Oxford, v. 65, p. 207-235, 2017, p. 212.

24 "O Eurocentrismo pode descrever modelos convencionais de pesquisa nos quais o Ocidente é moldado como agente da história universal e o restante é medido em termos de sua semelhança com o mesmo. Ou pode se referir à confiança de que o Ocidente é a última fonte do iluminismo no mundo moderno, de ideias como liberdade e igualdade. Mas, no sentido mais amplo, o Eurocentrismo se refere ao hábito geral de atribuir autoridade apenas a certas formas de conhecimento - enquanto se despreza e se deprecia outras". Tradução livre de: "Eurocentrism may describe conventional research models in which the West is cast as the agent of universal history and the rest are measured in term of their resemblance to It. Or it may refer to the confidence that the West is the ultimate source of enlightenment in the modern world, of ideas like freedom and equality. But in the broadest sense, Eurocentrism refers to the general habit of attributing authority to only certain forms of knowledge - what we might generally refer to as western rationality - while disregarding and disparaging others" (MUNSHI, Sherally. Comparative law and decolonizing critique. American Journal of Comparative Law, Oxford, v. 65, p. 207-235, 2017, p. 224). 
O caminho pode ser o de praticar um comparativismo que compreenda o caráter estrangeiro não só daqueles além da fronteira, mas dos que fazem parte do mesmo e tradicional "Estado-nação": ele pode ser útil em identificar um pano-de-fundo jurídico que continuamente destaca o papel das instituições em prejuízo dos sujeitos minoritários que atuam politicamente. Não será à toa que Munshi tomará como referência o trabalho de Manisha Sinha, "The Slave's Cause: A History of Abolition", para destacar que foi a resistência escrava, e não o liberalismo burguês, o principal fator no movimento de libertação contra a escravidão. ${ }^{25}$

\section{COMPARATIVISMO E JUDICIALIZAÇÃO}

Nos Estados Unidos, um arquétipo de um certo "isolacionismo" constitucional, o debate sobre o comparativismo não deixou de chegar, ainda que muito mais tarde do que em outros países. Não se trata de supor que o Direito Comparado fosse desconhecido: a questão é que ele era muito mais uma disciplina de curiosidade acadêmica do que uma fonte recorrente de decisões judiciais e políticas públicas. Foram as decisões seminais da Suprema Corte nos casos Atkins v. Virginia, 536 U.S. 304 (2002), Lawrence v. Texas, 539 U.S. 558 (2003) e Roper v. Simmons, 543 U.S. 551 (2005), que forneceram os primeiros elementos para a inauguração de um debate judicial e acadêmico (em um sentido mais transversal). ${ }^{26}$ Os Justices da Suprema Corte Anthony Scalia e Stephen Breyer travaram um verdadeiro confronto a respeito da possibilidade de fundamentar decisões judiciais estadunidenses em fontes estrangeiras. ${ }^{27}$ É necessário destacar que esta tem sido uma das principais vertentes de discussão sobre as possibilidades de interseções entre ordens constitucionais estrangeiras e entre ordens nacionais e supranacionais, povoando um amplo debate na doutrina e teoria constitucionais atuais. ${ }^{28}$ Sobre o por quê de se recorrer ao Direito Constitucional Comparado, contudo, não se pode aderir apenas à uma justificativa como a do Justice Stephen Breyer de que uma "sensibilidade cosmopolita" é sempre melhor. ${ }^{29}$ É claro que é preciso ir além.

25 Ver SINHA, Manisha. The Slave's Cause: A History of Abolition. New Haven: Yale University Press, 2016.

26 Os casos discutiam, respectivamente, a aplicação de pena de morte a pessoas com deficiências mentais, a criminalização de condutas homoafetivas pelos Estados e a aplicação de pena de morte a menores. Para uma recuperação desses e outros casos, assim como de negativas de certiorari (impedindo, pois, que um caso deságue na Suprema Corte dos Estados Unidos), ver: CHOUDHRY, Sujit. Migration as a new metaphor in comparative constitutional law. In: CHOUDHRY, Sujit (org.). The Migration of Constitutional Ideas. Cambridge: Cambridge University Press, 2006, p. 2.

27 Ver DORSEN, Norman. A Conversation between US Supreme Court Justices. International Journal of Constitutional Law, Oxford, v. 3, p. 519-541, n. 4, 2005.

28 Para tanto, com formas bastante diversas de abordagem, ver NEVES, Marcelo. Transconstitucionalismo. São Paulo:WMF Martins Fontes, 2008; JACKSON, Vicki. Constitutional Engagement in a Transnational Era. New York: Oxford University Press, 2010; WATERS, Melissa. Getting Beyond the Crossfire Phenomenon: A Militant Moderate's Take on the Role of Foreign Authority in Constitutional Interpretation. Fordham L. Rev., v. 77, 2008, p. 635-646.

29 CHOUDHRY, Sujit. Migration as a new metaphor in comparative constitutional law. In: CHOUDHRY, Sujit (org.). The Migration of Constitutional Ideas. Cambridge: Cambridge University Press, 2006, p. 6. 
Cheryl Saunders, ${ }^{30}$ ao percorrer o caminho de possibilidades do Direito Constitucional Comparado pela via da judicialização australiana, sustenta que duas eram as temáticas principais contra o uso de experiências estrangeiras em decisões judiciais: a) uma de cunho originalista, atribuível a Scalia, segundo a qual as fontes estrangeiras podem não ter sido objeto de deliberação nos processos constituintes que levaram à constituição de um determinado contexto; b) a segunda, levantada por Richard Posner, concerne a dificuldades metodológicas insuperáveis, como a impossibilidade de total conhecimento do contexto constitucional no qual se desenvolveram os elementos referidos. ${ }^{31}$

No que concerne à crítica sobre a legitimidade, é preciso referenciar que ela pressupõe uma leitura bastante restrita das diversas nuances percorridas por esta que poderíamos chamar de uma "judicialização comparada": um uso leve das práticas, exemplificado por referências a experiências internacionais, pelas menções a dados empíricos a respeito da prática de princípios em outras ordens ou menção a contextos estrangeiros para direcionar uma determinada decisão da corte que, contudo, se funda em argumentos domésticos. Há, contudo, também um uso mais profundo em que são emprestados argumentos de cortes estrangeiras, recorre-se ao direito estrangeiro para embasar a interpretação de um dispositivo constitucional ou, ainda, o direito estrangeiro aparece como elemento empírico que justifica o transplante de direito ou instituto estrangeiro. ${ }^{32}$

A discussão é ainda sofisticada na direção de se apartar um uso construtivo do direito estrangeiro, que passa a agir como guia em direções que poderiam ser julgadas como positivas ou negativas, de um uso reflexivo, permitindo que o mesmo direito estrangeiro sirva para direcionar os juízes para as potencialidades dos seus próprios sistemas jurídicos - é dizer, passa a ser necessário explorar as vantagens e desvantagens de uma decisão ou instituto no seu próprio espaço de nascimento. Pode-se ainda discutir se o recurso ao direito comparado significa um "método interpretativo" ou mesmo um valor ideológico; e, mesmo, se há que se falar em um diálogo.

É assim, por exemplo, que Saunders enxergará o modo como a Suprema Corte da Austrália fundamentou sua decisão em Australian Capital Television Pty. Ltd. v. Commonwealth, (1992) 177 C.L.R. 106, um caso em que estava em jogo a validade de uma lei da Commonwealth que proibia propaganda política televisionada no período anterior a eleições gerais, regionais ou locais. ${ }^{33}$ Por não haver uma declaração de direi-

30 SAUNDERS, Cheryl. The Use and Misuse of Comparative Constitutional Law. Indiana Journal of Global Legal Studies, New York, v. 13, p. 37-76, n. 1, 2006, p. 45.

31 Ver POSNER, Richard. No thanks, we already have our own laws. Legal Aff, [s.I.], jul./ago. 2004, p. 40. Disponível em: <http://www.legalaffairs.org/issues/July-August-2004/feature_posner_julaug04.msp>. Acesso em: 02 out. 2019.

32 SAUNDERS, Cheryl. The Use and Misuse of Comparative Constitutional Law. Indiana Journal of Global Legal Studies, v. 13, n. 1, 2006, p. 50.

33 SAUNDERS, Cheryl. The Use and Misuse of Comparative Constitutional Law. Indiana Journal of Global Legal Studies, New York, v. 13, p. 37-76, n. 1, 2006, p. 45. 
tos australiana, colocou-se em discussão a possibilidade de se falar em uma liberdade política derivada do sistema representativo institucionalizado constitucionalmente. ${ }^{34}$ Ao rechaçar uma vinculação ao sistema constitucional estadunidense e afirmar uma filiação ao sistema representativo britânico - qualificando a Constituição australiana como parte de um "direito estatutário" (statutory law) de especial dignidade diferente daquele norte-americano -, a Suprema Corte faria um trabalho comparativo dialógico.

A oposição à busca judicial pelo direito estrangeiro funda-se também em problemas de ordem metodológica. Em verdade, seria preciso separar de modo mais analítico a dimensão da argumentação judicial e a metodologia do Direito Comparado. Saunders destaca que uma questão diz respeito à qual seria a relação adequada entre direito nacional e estrangeiro quando de um julgamento perante uma corte. ${ }^{35} \mathrm{~A}$ segunda questão apontada liga-se ao potencial uso manipulativo do direito estrangeiro (uso esse que pode ser doméstico também, mas que, nesse caso, se curva a padrões mais assentados dentro do contexto), concretizada na expressão cherry-picking: decisões e institutos estrangeiros interessariam apenas para justificar uma posição de antemão já estabelecida. ${ }^{36}$

Em termos propriamente metodológicos, o Direito Comparado pode apresentar limitações bastante intuitivas, como o acesso, manejo e compreensão de fontes estrangeiras, como também um desafio mais significativo: como conhecer adequadamente o contexto em que se deu produziu a fonte. Todos esses obstáculos podem produzir o que é chamado de um "mau uso" do direito comparado por meio do qual juízes e cortes limitam arbitrariamente as jurisdições a que se referem, não justificando o resultado da seleção. Para tentar orientar e evitar dito "mau uso", Saunders aponta cinco pautas, das quais traremos à discussão apenas quatro, em vista do contexto eminentemente de Commonwealth da última. ${ }^{37} \mathrm{~A}$ uma, se a corte se propõe a um maior diálogo, diminui-se a necessidade de um profundo conhecimento contextual da fonte. A duas, a metodologia aparece como um embaraço se o judiciário visa apenas "transplantar" a solução

\footnotetext{
34 A Constituição australiana data de 1901.

35 SAUNDERS, Cheryl. The Use and Misuse of Comparative Constitutional Law. Indiana Journal of Global Legal Studies, New York, v. 13, p. 37-76, n. 1, 2006, p. 66.

36 Nas audiências de confirmação de sua indicação perante o Senado estadunidense, o atual Chief Justice John Roberts afirmou que essa justificativa transnacional pós-decisão equivaleria a olhar uma multidão e escolher seus amigos (CHOUDHRY, Sujit. Migration as a new metaphor in comparative constitutional law. In: CHOUDHRY, Sujit (org.). The Migration of Constitutional Ideas. Cambridge: Cambridge University Press, 2006, p. 7).

37 Saunders (SAUNDERS, Cheryl. The Use and Misuse of Comparative Constitutional Law. Indiana Journal of Global Legal Studies, New York, v. 13, p. 37-76, n. 1, 2006, p. 65) refere-se à English Practice Direction on the Citation of Authorities, que requer que advogados perante cortes do Reino Unido justifiquem o recurso ao direito estrangeiro. Apesar de ser esta uma demanda para as partes e seus advogados, ela acredita que a normativa coopera para um uso mais refletido do direito comparado. Ver Practice Direction (Citation of Authorities), (2001) 1 W.L.R. 1001 (Eng.). Disponível em <http://www.hmcourts-service.gov.uk/cms/814.htm> Acesso em 18 fev 2019).
} 
jurídica de outro contexto, guiando-se por razões funcionais e segundo uma lógica não reflexiva, mas construtiva (em um mal sentido). A três, quanto maior o alcance do uso do direito estrangeiro, mais importante que direcionamentos metodológicos sejam apontados pela própria corte.

Por estar imerso em uma tradição de common law (no que ainda a distinção com ordens de civil law tem pertinência), o trabalho de Saunders aponta que o uso do Direito Comparado interage com o procedimento judicial do common law - esta sua quarta pauta. ${ }^{38}$ Por exemplo: a obrigatoriedade de que os advogados das partes citem certas autoridades; erros e omissões de uma parte podem ser explorados pela parte adversa; defeitos argumentativos podem ser explorados por votos minoritários, comentadores e pela própria esfera pública. Estes instrumentos são também úteis se trazidos para o campo do manejo do Direito Comparado.

Não menos influente foi o estudo apresentado por Vicki Jackson, Constitutional Engagement in a Transnational Era. Ela apresentou três modelos de relação de decisões de juízes e tribunais domésticos com corte estrangeiras e transnacionais. A relação pode ser, em primeiro lugar, de resistência: cortes assumiriam uma posição em relação às constituições de afirmação auto-identitária que não permitiria a referência a precedentes e fontes alienígenas. Justices da Suprema Corte Estadunidense como John Roberts e Samuel Alito seguiriam uma posição desse tipo, além, é claro, do que já o fizera Scalia. Em segundo lugar, pode-se estar diante de posições de convergência. Haveria uma predisposição a aceitar normas, por exemplo, do Direito Internacional dos Direitos Humanos, como informativas da interpretação de normas constitucionais; ao lado desse motivo, situações como o pertencimento à União Europeia ou à Commonwealth dirigiriam decisões judiciais. Jackson cita os casos dos arts. 93 da Constituição Colombiana, de 1991, 75, inc. 22, da Constituição Argentina e $4^{\circ}$ das disposições provisórias da Constituição Peruana de 1993. ${ }^{39}$

O modelo decisional de engajamento, de seu turno, apresenta um posicionamento de maior abertura, em que elementos de autorreflexão desempenham um papel significativo. De um lado, o engajamento deliberativo assume que há uma permissibilidade ou abertura do sistema ao Direito Internacional e ao direito estrangeiro: seria o caso do voto da Justice Sandra Day O'Connor em Roper v. Simmons, 543 U.S. 551 (2005), que declarou inconstitucional a pena de morte para adolescentes. Houve uma refutação explícita de uma divisão estanque entre o direito estadunidense e tendências globais, não sem antes exigir um exame detalhado de normas e práticas dos Estados da federação. De outro lado, o engajamento relacional pressupõe que, necessariamente,

38 SAUNDERS, Cheryl. The Use and Misuse of Comparative Constitutional Law. Indiana Journal of Global Legal Studies, New York, v. 13, p. 37-76, n. 1, 2006, p. 74.

39 JACKSON, Vicki. Constitutional Engagement in a Transnational Era. New York: Oxford University Press, 2010, p. 43. 
o Direito Internacional e o direito estrangeiro sejam verificados, cabendo ao juiz ou à corte decidir por sua incidência efetiva no caso concreto. Na África do Sul, por exemplo, "[...] a demanda [constitucional] é procedimental, não substantiva: as cortes devem considerar o direito internacional, mas a constituição não requer conformidade".40 Nota-se, portanto, que a discussão sobre o papel do Direito Constitucional Comparado passa também pelo enfrentamento dos limites e possibilidades da atuação jurisdicional.

\section{EMPRÉSTIMOS CONSTITUCIONAIS, TRANSPLANTES JURÍDI- COS, MIGRAÇÃO DE IDEIAS CONSTITUCIONAIS: QUAL METÁ- FORA?}

Desde o final dos anos 1990, a teoria constitucional tem procurado lidar com o fenômeno de retorno do comparativismo recorrendo a metáforas diversas. Choudhry alude ao precursor estudo de Alan Watson, "Legal Transplants: An Approach to Comparative Law" que inauguraria o debate sobre a pertinência de "transplantes jurídicos" ou legal transplants. ${ }^{41}$ Choudhry recupera o debate travado entre aqueles que, como Pierre Legrand, sustentariam a impossibilidade do transplante, uma vez que normas jurídicas seriam tão cultural e socialmente embebidas que a transposição deveria ser não só do resultado, mas também de todo o processo que nelas (normas jurídicas) culmina; ao passo que James Whitman e David Nelken fariam importantes advertências no sentido de que há processos efetivos que ocorrem transculturalmente e que não podem ser ignorados por um impulso pela convergência. ${ }^{42}$

É assim que uma recorrente metáfora no Direito Constitucional Comparado também não seria imune a críticas: "empréstimos constitucionais" ou constitutional borrowing. Kim Lane Scheppele relembra que pensar em um empréstimo (ou um

\footnotetext{
40 Tradução livre de: "The requirement is procedural, not substantive: the courts must consider international law, but the constitution does not require conformance" (JACKSON, Vicki. Constitutional Engagement in a Transnational Era. New York: Oxford University Press, 2010, p. 78). Para um debate a respeito da relação entre as categorias de Jackson e a justiça transicional no Brasil, ver Torelly (TORELLY, Marcelo. Governança Transversal dos Direitos Fundamentais. Rio de Janeiro: Lumen Juris, 2016), Patrus (PATRUS, Rafael Dilly. Articulação Constitucional e Justiça de Transição. Belo Horizonte: D'Plácido, 2016) e Tirado (TIRADO, Felipe Guimarães Assis. Human Rights, Transitional Justice and Transnational Law: Towards Accountability for Crimes Against Humanity in Brazil. Belo Horizonte, 2018. 185 f. Dissertação de Mestrado. Programa de Pós-Graduação em Direito, UFMG).

41 CHOUDHRY, Sujit. Migration as a new metaphor in comparative constitutional law. In: CHOUDHRY, Sujit (org.). The Migration of Constitutional Ideas. Cambridge: Cambridge University Press, 2006, p. 17.

42 Não se deve, contudo, deixar de considerar o que se segue: "Como têm sublinhado alguns teóricos do Direito Constitucional Comparado, a prática da citação não pode se transformar num mero "transplante" de fontes jurídicas estrangeiras; ela deve ser feita conforme pautas metodológicas claras e pré-definidas, que auxiliem os juízes a utilizá-las apenas como um complemento da motivação da decisão" (VALE, André Rufino do. O argumento comparativo na jurisdição constitucional. Conjur. Diponível em <https://www.conjur. com.br/2014-mai-03/observatorio-constitucional-argumento-comparativo-jurisdicao-constitucional\#_ftnref4_7296>. Acesso em: 14 fev. 2019., p. 1).
} 
comodato) constitucional envolveria a necessidade de um futuro retorno do objeto emprestado, ${ }^{43}$ e mais, deveria haver permissão inicial para o empréstimo e até eventual melhora no objeto após sua devolução. Isto não acontece no modo como convencionalmente se usou a expressão "empréstimo constitucional". Daí ela propor a ideia de uma "influência constitucional cruzada" ou cross constitutional influence. ${ }^{44}$ Esse termo seria mais abrangente, envolvendo influências positivas e negativas, diretas e indiretas. Scheppele faz a percuciente afirmação de que, principalmente em momentos constituintes, pode ser mais importante negar o que um sujeito constitucional não é, ou não pode ser, do que fazer difíceis ilações sobre o que o futuro pode aguardar.

Isto permitiria distinguir entre um constitucionalismo aspiracional, em que tanto no processo constituinte como na interpretação importa mais olhar para o futuro e definir quais objetivos devem estar em jogo, e um constitucionalismo aversivo, no qual há uma definição clara do que se quer evitar, fazendo-se uma rejeição de uma possibilidade constitucional. Nesse último sentido, o preâmbulo da Lei Fundamental de Bonn, de 1949, ao invocar uma consciência da responsabilidade perante Deus e os homens do povo alemão, teria feito uma clara rejeição do passado nacional-socialista. De modo semelhante, o preâmbulo da Constituição Sul-Africana, de 1996, começa com a eloquente afirmação de que o povo daquele país reconhece as injustiças do passado. Poder-se-ia adicionar o modo como o preâmbulo da Constituição da Tunísia, de 2014, se orgulhar da luta de seu povo pela liberdade contra a tirania. Esses cortes epistemológicos são importantes, mas não se deve deixar de considerar que o constitucionalismo deve ter sempre um olhar dirigido tanto ao passado quanto ao futuro.

Fala-se, também, em "diálogos" entre cortes, ou na "migração de ideias constitucionais" (migration of constitutional ideas), como prefere Choudhry, ${ }^{45}$ uma expressão que parece tentar abranger vários fenômenos: por que aderir a um precedente estrangeiro, por que rejeita-lo, quais fundamentos estão em jogo, até onde se explorou o contexto sócio-político da decisão referenciada, entre outros. O que se deve assinalar, desse modo, é que não se pode ter uma atitude inocente em relação ao estrangeiro e ao supranacional. E talvez esta seja mais uma questão de metodologia do que de metáforas.

43 SCHEPPELE, Kim Lane. Aspirational and Aversive Constitutionalism: The Case for Studying Cross-Constitutional Influence Through Negative Models. I.CON, Oxford, v. 1, n. 2, p. 296-324. 2003, p. 296.

44 O termo remete à tipologia proposta por Anne-Marie Slaughter (SLAUGHTER, Anne-Marie. A Typology of Transjudicial Communication. U. Rich. L. Rev., Richmond, v. 29, n. 99, p. 99-137. 1994, p. 99) sobre a comunicação judicial, que envolveria: comunicação horizontal, comunicação vertical; comunicação vertical-horizontal mista; diálogo direto; monólogo; diálogo intermediado. Essas comunicações poderiam cumprir funções de: melhorar a efetividade de decisões de tribunais supranacionais; assegurar e promover a aceitação de obrigações internacionais recíprocas; fertilização cruzada; melhorar a persuasão, autoridade ou legitimidade de decisões judiciais individuais; e, promover deliberação coletiva.

45 CHOUDHRY, Sujit. Migration as a new metaphor in comparative constitutional law. In: CHOUDHRY, Sujit (org.). The Migration of Constitutional Ideas. Cambridge: Cambridge University Press, 2006, p. 22. 


\section{QUEM IMPORTA NO DIREITO CONSTITUCIONAL COMPARADO?}

Com todas as mudanças no interesse científico por ordens constitucionais fora do norte global, ainda assim, o movimento tem sido menos expansivo do que deveria. Tushnet e Khosla, por exemplo, destacam que a Ásia Oriental (China, Japão, Mongólia, Singapura, Indonésia, Coréia do Sul, entre outros) tem recebido mais atenção que o Sul Asiático ou Ásia Meridional, com exceção, em alguns aspectos, da Índia (a se incluir, pois, Paquistão, Nepal, Bangladesh, Sri Lanka, Afeganistão, Maldívias, Sudão, Mianmar). ${ }^{46}$ Cinco dos países da Ásia Meridional (Bangladesh, Índia, Nepal, Paquistão e Sri Lanka) compartilham elementos de desenvolvimento constitucional em meio a tensas relações entre direito e política. É claro que constituições e constitucionalismo canalizam um encontro entre os sistemas do direito e da política que precisa ser devidamente mediado. Mas há aspectos interessantes naquela região que podem iluminar a forma como se pensa o Direito Constitucional no Brasil e na América Latina, para além de uma leitura com os olhos direcionados para o norte - como parece ter sido a tradição recorrente. É claro que isto deve ser feito a partir de um ponto de vista dirigido contextualmente para problemas levantados pelos próprios atores constitucionais; só assim, a comparação pode se tornar plausível, como ressalta Choudhry em relação à Ásia Meridional, Turquia e Espanha e suas preocupações com políticas constitucionais de línguas oficiais. ${ }^{47}$

É aqui que se deveria, segundo Tushnet e Khosla, falar de um constitucionalismo instável. ${ }^{48}$ Esta seria uma tipologia de constitucionalismo que se refere à ação de atores comprometidos com a ideia de constitucionalismo, ainda que exigências liberais nem sempre estejam presentes, mas há um desejo de governança estável a ser consolidada. A expressão é indicativa de quais caminhos importam no Direito Constitucional Comparado e se podemos segmentar arbitrariamente a investigação científica. Elementos como federalismo simétrico e assimétrico, reconhecimento de plurinacionalismo, multiculturalismo, estariam presentes, mas opções constitucionais interessantes de diversos pontos de vista competiriam entre si de uma forma a evitar a consolidação de um só paradigma. O direito enfrentaria obstáculos significativos para mediar fatores sociais que empurram esses países para a instabilidade institucional. Questões como desenho institucional ainda são problemáticas para todo o sistema, mais do que o papel de cortes constitucionais ou da interpretação constitucional. ${ }^{49}$ De todo modo, a tendência das

46 TUSHNET. Mark, KHOSLA, Madhav. Unstable Constitutionalism. In: TUSHNET, Mark. KHOSLA, Madhav (orgs.). Unstable Constitutionalism: Law and politics in South Asia. Cambridge: Cambridge University Press, p. 3.

47 CHOUDHRY, Sujit. How To Do Constitutional Law and Politics in South Asia. In: TUSHNET, Mark. KHOSLA Madhav (orgs.). Unstable Constitutionalism: Law and politics in South Asia. Cambridge: Cambridge University Press, p. 19.

48 TUSHNET. Mark, KHOSLA, Madhav. Unstable Constitutionalism. In: TUSHNET, Mark. KHOSLA, Madhav (orgs.). Unstable Constitutionalism: Law and politics in South Asia. Cambridge: Cambridge University Press, p. 5.

49 Ante o cenário jurídico-político brasileiro pós-2016, há suficientes razões para questionar o modo como se aplica a Constituição brasileira de 1988, para muito além dos problemas recorrentes que afligem 
partes em conflito nesses países seria a de busca de uma definição constitucional do tipo de Estado que pretendem e não de colocar fim ao projeto comum.

É, assim, um problema central problematizar a ideia de instabilidade constitucional. Fontes para tal fenômeno podem ser externas a ele, mas também podem incluir a atuação de instituições que fazem parte do próprio sistema constitucional. Parte da tarefa consiste justamente na identificação das fontes de instabilidade e na apresentação de respostas. A questão é que, diante de uma instabilidade que é constitucional, as respostas não podem partir apenas da política, mas devem vir também do direito, ou melhor, da abordagem jurídica da forma constitucional. ${ }^{50}$ Será que essa não é uma questão que interessa à América Latina?

Fontes de instabilidade constitucional podem se apresentar por meio das instituições que rompem com as formas tradicionais de fixação de fronteiras de divisão de trabalho. Análises de fatores desse tipo demandam mais e mais dos estudiosos do constitucionalismo comparado. A investigação de propostas de constitucionalismo que ultrapassam o enquadramento liberal demonstra que se deve evitar o que se poderia chamar de segmentação comparada, ou seja, dar privilégio excessivo a paradigmas constitucionais tradicionais que podem impedir o contato com experiências menos frequentes de comparativismo.

\section{TRANSDISCIPLINARIEDADE NOS ESTUDOS CONSTITUCIONAIS COMPARADOS}

Se é possível remontar a fontes bastante remotas do Direito Comparado, como o faz Hirschl, ${ }^{51}$ voltando a normas religiosas pré-modernas e passando por Bodin, Selden e Montesquieu, de outra parte, a contemporaneidade, além de resgatar os estudos constitucionais comparados, demanda transdisciplinariedade para lidar com a complexidade. Talvez por isso faça mais sentido falar em "Estudos Constitucionais Comparados", ao

constitucionalistas brasileiros. Quais os limites para o uso (ou mau uso) do impeachment no Brasil e em países latino-americanos? A judicialização da política e a politização da justiça foram tão longe a ponto de romper com a ordem institucional de 1988? Há espaço para uma constituição dirigente ante uma emenda constitucional que institui, na visão de alguns (STRECK, Lênio. Check list: 21 razões pelas quais já estamos em Estado de exceção. Conjur. Disponível em: <https://www.conjur.com.br/2017-jun-29/senso-incomum-check-list-21-razoes-pelas-quais-estamos-estado-excecao>. Acesso em: 18 fev. 2019, p. 1), um estado de exceção econômico?

50 "Implícito é o entendimento de que normas e instituições jurídicas também têm o potencial de moldar realidades sócio-políticas na sua própria forma distinta: por estas razões, o desenho jurídico importa. O fenômeno específico do constitucionalismo instável existe porque o direito é trazido à discussão em meio à política". Tradução livre de: "Implicit is an understanding that legal norms and institutions also have the potential to shape sociopolitical realities in their own distinct fashion; for that reason, legal design matters. The precise phenomenon of unstable constitutionalism exists because law is brought into discussion with politics" (TUSHNET. Mark, KHOSLA, Madhav. Unstable Constitutionalism. In: TUSHNET, Mark. KHOSLA, Madhav (orgs.). Unstable Constitutionalism: Law and politics in South Asia. Cambridge: Cambridge University Press, p. 3).

51 HIRSCHL, Ran. Comparative Matters: The Renaissance of Comparative Constitutional Law. Oxford: Oxford University Press, 2014, p. 77. 
invés de "Direito Constitucional Comparado". Mais do que meramente citar dispositivos legais ou decisões judiciais descontextualizadas, é preciso avançar por opções metodológicas que vão além do estudo teórico. Este, de fundamental importância normativa, não pode ignorar questões empíricas. É claro que não se está aqui a renovar velha dicotomia law in books e law in action, de Roscoe Pound..$^{52}$ Há pressupostos hermenêuticos que não podem ser simplesmente ignorados. Por isto mesmo é que a transdisciplinariedade é um fator fundamental na investigação constitucional comparada: a separação das atividades de juristas, cientistas políticos e sociólogos é prejudicial.

Assim, e novamente com Hirschl, ${ }^{53}$ os fatores de necessidade, curiosidade e demanda política devem ser combinados com metodologias de análise que podem abrir o campo de interesse dos estudos comparados. Questões como comportamento judicial, dinâmicas de processos constituintes, formas de aprovação emendas constitucionais ou modelos de efetivação de decisões judiciais importam, desde que adequada e cientificamente apreendidos. Pode ser que o instrumental para esse tipo de análise escape de modo imediato ao jurista; é aí que o desenvolvimento de pesquisas com acadêmicos de outras áreas importa. E uma contestação que é feita por Hirschl é de extrema importância: ${ }^{54}$ enquanto as ciências sociais em geral avançaram muito em termos de estudos comparados, os juristas mantiveram-se limitados em termos metodológicos. Uma pressuposição simples decorrente disto é que constituições não se produzem no vácuo, estando diretamente relacionadas ao contexto político, econômico e social que buscam normatizar.

É importante, contudo, tentar entender o que significa produzir estudos em Direito Constitucional ou em Direito Constitucional Comparado de modo atento a dados empíricos. Não nos parece, assim, acertada a crítica de Hirschl a Dworkin no sentido de que nenhuma de suas seis grandes obras recorre a dados empíricos para entender as origens e consequências do constitucionalismo e do controle de constitucionalidade (judicial review). ${ }^{55}$ Pois tratar o direito como um empreendimento interpretativo nada mais exige do que tomar em consideração dados empíricos, principalmente os que circundam um caso concreto posto à disposição de um juiz ou um tribunal. $O$ que indica que uma busca por respostas em sistemas constitucionais comparados exigirá muito mais do intérprete.

\footnotetext{
52 Ver POUND, Roscoe. Law in Books and Law in Action. Am. L. Rev., [s.I.], v. 44, n. 12, 1910, p. 12-36.

53 HIRSCHL, Ran. Comparative Matters: The Renaissance of Comparative Constitutional Law. Oxford: Oxford University Press, 2014, p. 13.

54 HIRSCHL, Ran. Comparative Matters: The Renaissance of Comparative Constitutional Law. Oxford: Oxford University Press, 2014, p. 152.

55 "Curiosamente, nenhum dos seis supostamente apaixonados livros de Ronald Dworkin sobre constitucionalismo cita nenhum trabalho empírico sobre as origens e consequências da constitucionalização e do controle de constitucionalidade". Tradução livre de: "Interestingly, none of Ronald Dworkin's six passionately argued books on constitutionalism cites any empirical work on the origins and consequences of constitutionalization and judicial review" (HIRSCHL, Ran. Comparative Matters: The Renaissance of Comparative Constitutional Law. Oxford: Oxford University Press, 2014, p. 152, nota 3).
} 
Talvez o problema esteja no ponto de partida: uma leitura positivista (com todas as reduções que podem caber nesse termo) do Direito Comparado pode resultar em um empréstimo constitucional equivocado justamente porque ignora aspectos econômicos, sociais ou políticos do contexto estrangeiro ou supranacional. Interpretar pede mais em termos de comparativismo. O que não significa que questões, por exemplo, de ordem econômica devam ganhar primazia sobre uma leitura normativa do direito.

\section{ANÁLISES SMALL-N E LARGE-N}

A recente literatura sobre Direito Constitucional Comparado alerta para a necessidade de dirigir adequadamente as formas de abordagem de fenômenos constitucionais, evitando-se generalizações indevidas. Ran Hirschl alerta para a necessidade de distinguir análises small- $N_{1}^{56}$ voltadas a um comparativismo de estudo de casos e mais prudente, já presentes no Direito Constitucional Comparado em geral. Elas são, contudo, deficientes quando o assunto é proceder a rigorosas metodologias que permitam conclusões mais precisas. De outra parte, a pesquisa estadunidense tem se concentrado mais em estudos large- $N$, apresentando métodos de coleta de dados rigorosos e análises estatísticas. Elas não deixam, contudo, de ser problemáticas também. Observe-se, por exemplo, que o difundido estudo de Law e Versteeg, ${ }^{57}$ parte de um conceito reduzido de constituições como cartas de direitos somente, universaliza uma dicotomia em norma e fato já bastante questionada, por exemplo, no Direito Constitucional alemão e ainda elogia constituições como a saudita por uma suposta honestidade em preferir explicitamente aspirar menos liberdade de imprensa.

Exige-se, portanto, um esclarecimento dos objetivos do constitucionalista que trabalha comparativamente. É preciso delimitar que tipo de investigação está em jogo - analítica ou empírica - e quais reivindicações - baseada em dados ou normativa. Mas como destaca Hirschl, ${ }^{58}$ deve-se ter em mente que tais tipologias metodológicas não são mutuamente excludentes. Estudos small- $N$ e estudos large- $N$ não se opõem de modo absoluto.

\section{USOS EQUIVOCADOS DO DIREITO COMPARADO NO BRASIL}

O acesso e o manejo do Direito Comparado no Brasil nunca deixaram de ser problemáticos. Há obstáculos variados. Um primeiro seria de insuficiência. Se o Direito

\footnotetext{
56 HIRSCHL, Ran. Comparative Matters: The Renaissance of Comparative Constitutional Law. Oxford: Oxford University Press, 2014, p. 226.

57 LAW, David. VERSTEEG, Mila. Sham Constitutions. California Law Review, Berkeley, v. 101, n. 4, p. 863-925, 2013, p. 870.

58 HIRSCHL, Ran. Comparative Matters: The Renaissance of Comparative Constitutional Law. Oxford: Oxford University Press, 2014, p. 279.
} 
Comparado e o Direito Comparado Constitucional importam, principalmente em termos de atividade acadêmica e judicial, a tendência é que eles ocupem um lugar de quase "enobrecimento" dos produtos dessas atividades. Como destacou Conrado Hübner Mendes em relação às decisões do Ministro Luiz Fux do Supremo Tribunal Federal, ${ }^{59}$ pode às vezes sobrar "estrangeirismos" no lugar de análise cuidadosa de um caso concreto. Também em termos insuficiência, deve-se destacar que juízes tem um contato restrito tanto com a academia brasileira quanto com a academia estrangeira - aqui em um nível mais insatisfatório. Recente pesquisa da Associação dos Magistrados Brasileiros (AMB) demonstrou que, no quesito "Fundamentação das decisões judiciais", não obstante não se tenha investigado a persuasão de fontes e decisões estrangeiras e supranacionais, houve pergunta direcionada obras jurídicas de referência. Em relação a estas, apareceram poucos autores estrangeiros: $0,5 \%$ dos entrevistados falaram em Ale$x y ;{ }^{60}$ 0,3\%, em Kelsen e Dworkin; 0,2\%, em Beccaria e Bobbio; 0,1\%, em Luigi Ferrajoli, Piero Calamandrei e John Rawls. ${ }^{61}$

É claro que, como quaisquer dados empíricos, é preciso compreende-los. Eles escondem que juízes podem fazer referência a autores brasileiros que comungam (o que não é indispensável, é claro) de ideias estrangeiras ou supranacionais. Mas indica algumas percepções. Como declarou o jornalista Elio Gaspari, ${ }^{62}$ é estranho que se enfrente as difíceis consequências da delação premiada ou que se queira importa o plea bargain conhecendo apenas dois (na verdade, um) juristas estadunidenses.

Não são poucos os exemplos de problemas no manejo do Direito Constitucional Comparado e não teríamos todo o espaço necessário para aqui analisa-los. Fiquemos apenas com dois: um de aspecto jurisdicional e outro de aspecto acadêmico. No campo jurisdicional, o voto da Ministra Rosa Weber, do Supremo Tribunal Federal, no Habeas Corpus (HC) 152.752, ${ }^{63}$ impetrado pelo ex-Presidente Lula, indica uma frouxa funda-

59 MENDES, Conrado Hübner. Debaixo da toga de Fux, bate um coração. Época, 18 jan 2019. Disponível em: <https://epoca.globo.com/debaixo-da-toga-de-fux-bate-um-coracao-23381940>. Acesso em: 14 fev. 2019, p. 1.

60 O caso de Alexy é exemplar, uma vez que, desde o início de seus estudos no Brasil em meados da década de 1990, critica-se a apropriação acrítica, senão indevida da ponderação de valores. Para tanto, ver MEYER, Emilio Peluso Neder. Decisão e jurisdição constitucional: crítica às sentenças intermediárias, técnicas e efeitos do controle constitucionalidade em perspectiva comparada. Rio de Janeiro: Lumen Juris, 2017 e MORAES, Fausto de Santos. Ponderação e Arbitrariedade: A Inadequada Recepção de Alexy pelo STF. 2a ed. Salvador: Juspodivm, 2018. Aliás, a própria proporcionalidade é um exemplo de migração de ideias constitucionais exitoso, mas não imune a críticas. Ver, também, BARAK, Ahron. Proportionality: Constitutional Rights and Their Limitations. Cambridge: Cambridge University Press, 2012, e JACKSON, Vicki. TUSHNET, Mark (orgs.). Proportionality: New frontiers, new challenges. New York: Cambridge University Press, 2017.

61 VIANNA, Luiz Werneck; CARVALHO, Maria Alice Rezende de; BURGOS, Marcelo Baumann. Quem somos: a magistratura que queremos. Rio de Janeiro: Associação dos Magistrados Brasileiros, 2018, p. 133.

62 GASPARI, Elio. Os juízes no deserto de juristas. Folha de S. Paulo, 13 fev. 2019, Disponível em: <https://www1. folha.uol.com.br/colunas/eliogaspari/2019/02/os-juizes-no-deserto-de-juristas.shtml>. Acesso em: 14 fev. 2019.

63 BRASIL. Supremo Tribunal Federal. HC 152.752. Rel. Min. Edson Fachin. Voto Min. Rosa Weber. Brasília, 4 abr 2018. Disponível em: <https://www.conjur.com.br/dl/leia-voto-ministra-rosa-weber.pdf>. Acesso em: 18 fev. 2019. 
mentação que peca por uma referência talvez pré-disposta a um resultado que não se adequa às premissas fundamentadoras. Assim, um conhecido autor da teoria dos precedentes como Frederick Schauer é referenciado por uma citação em que se defende que tribunais não devem alterar seu entendimento no caso de mudanças de composição. ${ }^{64}$ Correta na premissa, a referência torna-se complicada quando se observar que nem o Supremo Tribunal Federal e nem os juízes brasileiros se importam tanto com o sistema de decisões vinculantes, mesmo com o fortalecimento posterior ao Código de Processo Civil brasileiro de 2015: segundo a referenciada pesquisa da AMB, à pergunta de se magistrados deveriam poder decidir sem se pautar necessariamente pelo sistema de súmulas e precedentes vinculantes, cerca 55\% dos membros de tribunais superiores responderam que concordam ou muito (30\%) ou pouco (25\%). Isto demonstra que a importação do sistema para o Brasil, que se inicia, pelo menos, com a Emenda Constitucional no 45/2004, não correspondeu efetivamente a uma mudança em quinze anos de vigência.

De modo semelhante, referências à integridade proposta por Ronald Dworkin são feitas de modo aleatório. $O$ autor estadunidense é invocado para justificar a necessidade de observar precedentes e respeito pela instituição e, como ele mesmo invocara, não em nome de uma coerência cega, mas, inclusive, superando precedentes. Em seguida, a tese de uma única resposta correta é sustentada, assim como a necessidade de separar a moralidade pessoal do juiz da moralidade política. ${ }^{65}$ Mas isto nunca significou para o autor um hiato entre o que defende o julgador e o que ele, de fato, entende como sendo a resposta correta. Se o próprio juiz não acredita ser aquela a resposta correta, por que ele deveria sustentar uma posição colegiada discordante da sua? ${ }^{66}$

64 SCHAUER, Frederick. Thinking Like a Lawyer: A New Introduction to Legal Reasoning. Cambridge, Massachusetts; London, England: Harvard University Press, 2009, p. 37.

65 MEYER, Emílio Peluso Neder; TIRADO, F. G. A. A relação entre direito e moral em Dworkin. In: ABBOUD, Georges; LEITE, George Salomão; ALMEIDA FILHO, Agassiz. (Org.). Ronald Dworkin: direito, política e pessoa humana. São Paulo: Tirant Brasil, 2018. p. 333-350.

66 "É claro, parece arrogante para pessoas sérias que insistam que haja então uma única verdade exclusiva a respeito da questão interpretativa à mão, ou que aqueles que não enxergam a lei ou a pintura como eles veem estão apenas errados. Parece mais realista e modesto dizer que não há uma única interpretação, mas somente diferentes respostas aceitáveis ou responsáveis.

E mesmo assim, isto é exatamente o que nós não devemos dizer se formos honestos, porque não é o que acreditamos ou podemos acreditar. Repetindo: um estudioso que trabalha por anos em uma nova leitura de Hamlet não pode acreditar que suas conclusões interpretativas variadas não são mais válidas que as conclusões contraditórias de outros estudiosos; um juiz que manda alguém para a cadeia baseado em uma interpretação do direito que ele acredita não ser melhor, porém apenas diferente de interpretações concorrentes deveria ele mesmo ser preso". Tradução livre de: "Of course, it seems arrogant to thoughtful people to insist that there is then one exclusive truth about the interpretive issue in hand, that those who do not see the statute or painting as they do are simply in error. It seems more realistic and modest to say that there is no one right interpretation but only different acceptable or responsible ones.

And yet that is exactly what we must not say if we are honest, because it is not what we believe or can believe. To repeat: a scholar who labors for years over a new reading of Hamlet cannot believe that his various interpretive conclusions are no more valid than the contradictory conclusions of other scholars; a judge who 
A decisão demonstra a distância entre uma análise profunda e uma análise superficial, nem tanto do Direito Comparado, mas da teoria comparada. ${ }^{67}$

No aspecto acadêmico, fiquemos apenas com um exemplo de uma publicação em um website jurídico de notícias, o Jota. Procurando justificar as afirmações do Governador do Rio de Janeiro eleito, Wilson Witzel, no sentido de que supostos criminosos que estivessem portando armas de uso exclusivo das Forças Armadas, Flávio Jardim, ${ }^{68}$ em um longo arrazoado, toma o direito estadunidense por referência. Logo na introdução, notase que não há nenhuma pretensão de se buscar algo nem próximo do que seria uma migração de ideias constitucionais: o autor destaca que empreenderá uma verificação da “(...) compatibilidade da proposta de Witzel com o direito vigente no país, à luz dos critérios do direito americano." Em seguida, ele passa à definição jurídica do que é o target killing nos Estados Unidos. É curioso que há o reconhecimento de que o direito de guerra não é o mesmo que o Direito Penal doméstico; mas este não pareceria ser o problema.

Segue-se uma análise dos critérios de "razoabilidade objetiva" e clear and presente danger da Suprema Corte Norte-Americana e a incorporação pela legislação estadual desses standards para situações em que acusados ofereçam perigo aos policiais. E daí, com base nesses critérios, ele elaborará a conclusão de que a proposta de Witzel “(...) dificilmente seria considerada inconstitucional”. Já que a Lei 13.497/2017 trataria como hediondos os crimes de posse de armas privativas das Forças Armadas, parece não haver problemas em comparar nosso caso com o norte-americano. $\mathrm{E}$ mesmo quando o autor passa para uma análise do Direito Penal brasileiro, nenhum paralelismo é desenvolvido. Perguntas como "qual o contexto de produção dos precedentes", "como o federalismo se relaciona com as decisões do tribunal", "Estados diversos podem regular diferentemente a questão", "quais aspectos sociais e legais poderiam ser destacados", "qual o alvo usual do policial de cada contexto", entre outras, são deixadas em aberto.

O "irônico" disto é que a campanha eleitoral de Witzel para o Governo do Estado do Rio de Janeiro oscila, até o momento, entre bravata de campanha e estímulo à violência. Após ele afirmar que “(...) O correto é matar o bandido que está de fuzil. A polícia vai fazer o correto: vai mirar na cabecinha e... Fogo!", uma chacina no morro do Fallet deixou o saldo de treze mortos com indícios de tortura e mortes à facada

sends someone to jail on an interpretation of the law he believes no better than, but only diff erent from, rival interpretations should be jailed himself" (DWORKIN, Ronald. Justice for Hedgehogs. Cambridge, MA; London, England: The Belknap Press of Harvard University Press, 2011, p. 151).

${ }^{67}$ Ainda no aspecto jurisdicional, muito do que se discutiu prévia e posteriormente ao julgamento de viragem jurisprudencial sobre a presunção de inocência em termos comparados era baseado no "adágio popular" "só no Brasil é assim". Para uma crítica, ver MEYER, Emílio Peluso Neder. Presunção de inocência até a segunda instância?. JOTA, 19 fev. 2016. Disponível: <https://www.jota.info/opiniao-e-analise/artigos/presuncao-de-inocencia-ate-a-condenacao-em-segunda-instancia-19022016>.

68 JARDIM, Flávio. "Atiradores de elite e o Direito". Jota, 21 nov. 2018. Disponível em: <https://www.jota.info/ opiniao-e-analise/artigos/atiradores-de-elite-e-o-direito-21112018>. Acesso em: 14 fev. 2019, p. 1. 
após rendição. ${ }^{69}$ Vê-se que a pergunta sobre as condições de ação da polícia brasileira comparativamente à americana (que também tem alvos preferenciais), de fato, fez falta no estudo acima apontado.

\section{CONCLUSÕES}

O artigo buscou reconstruir algumas das principais inquietações que cercam o Direito Constitucional Comparado. Os resultados de pesquisa indicaram que ainda permanece uma forte demanda por rigor metodológico no campo. Saber as perguntas adequadas a fazer pode permitir um uso de fontes comparadas que de fato importe, tanto para a academia quanto para a aplicação do direito, em ganhos. Muito do uso que se tem feito de fontes comparadas tem se mantido no campo de tentativas de fortalecimento de argumentos que previamente são escolhidos de acordo com um resultado esperado. Perde-se, portanto, no espaço argumentativo e interpretativo e distorce-se a fonte em prol de um objetivo específico. Os dois exemplos analisados (o voto da Ministra Rosa Weber no HC 152.752 e a importação do target killing) indicaram que os problemas metodológicos são, não raro, ignorados quando se fala de Direito Comparado no Brasil. Este artigo busca, ainda que de forma limitada, estimular o debate para propor novas pautas no Direito Constitucional Comparado.

Evitar o recurso excessivo a modelos do norte global e recorrer cada vez mais à transdisciplinariedade parecem ser as questões mais urgentes para o comparativismo no Brasil. É claro que não se deve propor um fechamento nacionalista equivocado. A questão está muito mais em fortalecer pontes de ligação entre experiências diversas, talvez no sentido do que Roland Robertson chamou de "glocalização", ou seja, a manutenção de uma constante tensão entre o local e global. ${ }^{70}$ Esse tipo de abordagem exige, contudo, tanto a assunção de um olhar transdisciplinar, que permita ao jurista transbordar os limites tradicionais da ciência jurídica, quanto um ponto de vista não subordinado às práticas impositivas das democracias ocidentais.

\section{REFERÊNCIAS}

ALBURQUERQUE, Ana Luiza. Defensoria vê indícios de mutilações em operação da PM que deixou 13 mortos no Rio. Folha de S. Paulo, 12 fev 2019. Disponível em: < https://www1.folha.uol.com. $\mathrm{br} /$ cotidiano/2019/02/defensoria-do-rio-ve-indicios-de-fuzilamento-em-acao-policial-que-matou-13.shtml>. Acesso em:18 fev. 2019.

69 ALBURQUERQUE, Ana Luiza. Defensoria vê indícios de mutilações em operação da PM que deixou 13 mortos no Rio. Folha de S. Paulo, 12 fev. 2019. Disponível em: <https://www1.folha.uol.com.br/cotidiano/2019/02/defensoria-do-rio-ve-indicios-de-fuzilamento-em-acao-policial-que-matou-13.shtml>. Acesso em:18 fev. 2019 , p. 1. 70 ROBERTSON, Roland. Glocalization: Time-Space and Homogeneity-Heterogeneity. In: FEATHERSTONE, Mike. LASH, Scott. ROBERTSON, Roland (orgs.). Global Modernities. Londres: Sage, 1995, p. 25-44. 
BARAK, Ahron. Proportionality: Constitutional Rights and Their Limitations. Cambridge: Cambridge University Press, 2012.

BERNAL-PULIDO, Carlos. Transitional Justice within the Framework of a Permanent Constitution: The Case Study of the Legal Framework for Peace in Colombia. Cambridge J. Int'l \& Comp. L., Cambridge, v. 3, n. 4, p. 1136-1163, 2014.

BISCARETTI DE RUFFÌA, Paolo. Introducción al derecho constitucional comparado: las "formas de Estado" y las "formas de gobierno". Cidade do México: Fondo de Cultura Económica, 1996.

CATTONI DE OLIVEIRA, Marcelo Andrade. Contribuições para uma Teoria Crítica da Constituição. Belo Horizonte: Arraes Editores, 2017.

CHOUDHRY, Sujit. How to Do Constitutional Law and Politics in South Asia. In: TUSHNET, Mark. KHOSLA, Madhav (orgs.). Unstable Constitutionalism: Law and politics in South Asia. Cambridge: Cambridge University Press.

CHOUDHRY, Sujit. Migration as a new metaphor in comparative constitutional law. In: CHOUDHRY, Sujit (org.). The Migration of Constitutional Ideas. Cambridge: Cambridge University Press, 2006.

DANTAS, Ivo. Novo direito constitucional comparado. Curitiba: Juruá, 2010.

DORSEN, Norman. A Conversation between US Supreme Court Justices. International Journal of Constitutional Law, Oxford, v. 3, n. 4, p. 519-541, 2005.

DUTRA, Deo Campos. VIEIRA, José Ribas. “O Direito Constitucional Comparado entre Renascimento e Consolidação". Sequência, Florianópolis, n. 76, p. 69-94, 2017.

DWORKIN, Ronald. Justice for Hedgehogs. Cambridge, MA; London, England: The Belknap Press of Harvard University Press, 2011.

FIUZA, Ricardo Arnaldo Malheiros. Direito Constitucional Comparado. 4a ed. Belo Horizonte: Del Rey, 2004.

FREIRE, Alonso. "Interpretação constitucional comparativa: aproximação crítica e arcabouço metodológico". Revista Publicum, n. 2, p. 45-73. 2016.

GARCÍA-PELAYO, Manuel. Derecho constitucional comparado. Madri: Alianza Universidad Textos, 1993.

GASPARI, Elio. Os juízes no deserto de juristas. Folha de S. Paulo, 13 fev. 2019. Disponível em: <https://www1.folha.uol.com.br/colunas/eliogaspari/2019/02/os-juizes-no-deserto-de-juristas. shtml>. Acesso em: 14 fev. 2019.

GINSBURG, Tom. Judicial Review in New Democracies: Constitutional Courts in Asian Cases. Cambridge: Cambridge University Press, 2003.

HIRSCHL, Ran. Comparative Matters: The Renaissance of Comparative Constitutional Law. Oxford: Oxford University Press, 2014. 
HIRSCHL, Ran. Towards Juristocracy: The Origins and Consequences of the New Constitutionalism. New Haven: Harvard University Press, 2004.

JACKSON, Vicki. Constitutional Engagement in a Transnational Era. New York: Oxford University Press, 2010.

JACKSON, Vicki. TUSHNET, Mark (orgs.). Proportionality: New frontiers, new challenges. New York: Cambridge University Press, 2017.

JARDIM, Flávio. "Atiradores de elite e o Direito". Jota, 21 nov. 2018. Disponível em: < https://www.jota. info/opiniao-e-analise/artigos/atiradores-de-elite-e-o-direito-21112018>. Acesso em: 14 fev. 2019.

LAW, David. VERSTEEG, Mila. Sham Constitutions. California Law Review, Berkeley, v. 101, n. 4, p. 863-952, 2013.

LEGRAND, Pierre. Jameses at Play: A Tractation on the Comparison of Laws. The American Journal of Comparative Law, Oxford, v. 65, p. 1-132, 2017.

MENDES, Conrado Hübner. Debaixo da toga de Fux, bate um coração. Época, 18 jan. 2019. Disponível em: <https://epoca.globo.com/debaixo-da-toga-de-fux-bate-um-coracao-23381940>. Acesso em: 14 fev. 2019.

MEYER, Emilio Peluso Neder. Decisão e jurisdição constitucional: crítica às sentenças intermediárias, técnicas e efeitos do controle constitucionalidade em perspectiva comparada. Rio de Janeiro: Lumen Juris, 2017.

MEYER, Emílio Peluso Neder. Judges and Courts Destabilizing Constitutionalism: The Brazilian Judiciary Branch's Political and Authoritarian Character. German Law Journal, v. 19, p. 727-768, 2018.

MEYER, Emílio Peluso Neder. Presunção de inocência até a segunda instância?. JOTA, 19 fev. 2016. Disponível em: <https://www.jota.info/opiniao-e-analise/artigos/presuncao-de-inocencia -ate-a-condenacao-em-segunda-instancia-19022016>.MORAES, Fausto de Santos. Ponderação e Arbitrariedade: A Inadequada Recepção de Alexy pelo STF. 2ª ed. Salvador: Juspodivm, 2018.

MEYER, Emílio Peluso Neder; TIRADO, F. G. A. A relação entre direito e moral em Dworkin. In: ABBOUD, Georges; LEITE, George Salomão; ALMEIDA FILHO, Agassiz. (Org.). Ronald Dworkin: direito, política e pessoa humana. São Paulo: Tirant Brasil, 2018. p. 333-350.

MUNSHI, Sherally. Comparative law and decolonizing critique. American Journal of Comparative Law, Oxford, v. 65, p. 207-235, 2017.

NEVES, Marcelo. Transconstitucionalismo. São Paulo: WMF Martins Fontes, 2008.

PATRUS, Rafael Dilly. Articulação Constitucional e Justiça de Transição. Belo Horizonte: D'Plácido, 2016.

POSNER, Richard. No thanks, we already have our own laws. Legal Aff, [s.l.], jul./ago. 2004.

POUND, Roscoe. Law in Books and Law in Action. Am. L. Rev., [s.I.], v. 44, n. 12, p. 12-36, 1910. 
ROBERTSON, Roland. Glocalization: Time-Space and Homogeneity-Heterogeneity. In: FEATHERSTONE, Mike. LASH, Scott. ROBERTSON, Roland (orgs.). Global Modernities. Londres: Sage, 1995, p. 25-44.

SAUNDERS, Cheryl. The Use and Misuse of Comparative Constitutional Law. Indiana Journal of Global Legal Studies, New York, v. 13, n. 1, p. 37-76, 2006.

SCHAUER, Frederick. Thinking Like a Lawyer: A New Introduction to Legal Reasoning. Cambridge, Massachusetts; London, England: Harvard University Press, 2009.

SCHEPPELE, Kim Lane. Aspirational and Aversive Constitutionalism: The Case for Studying Cross-Constitutional Influence Through Negative Models. I.CON, Oxford, v. 1, n. 2, p. 296-324, 2003.

SINHA, Manisha. The Slave's Cause: A History of Abolition. New Haven:Yale University Press, 2016.

SLAUGHTER, Anne-Marie. A Typology of Transjudicial Communication. U. Rich. L. Rev., Richmond, v. 29, n. 99 , p. 99-137, 1994.

STRECK, Lênio. Check list: 21 razões pelas quais já estamos em Estado de exceção. Conjur. Disponível em: <https://www.conjur.com.br/2017-jun-29/senso-incomum-check-list-21-razoes-pelasquais-estamos-estado-excecao >. Acesso em: 18 fev. 2019.

STRECK, Lênio. Jurisdição Constitucional. 5a ed. Rio de Janeiro: Forense, 2018.

TIRADO, Felipe Guimarães Assis. Human Rights, Transitional Justice and Transnational Law: Towards Accountability for Crimes Against Humanity in Brazil. Belo Horizonte, 2018. 185 f. Dissertação de Mestrado. Programa de Pós-Graduação em Direito, UFMG.

TORELLY, Marcelo. Governança Transversal dos Direitos Fundamentais. Rio de Janeiro: Lumen Juris, 2016.

TULLY, James. The Imperialism of Modern Constitutional Democracy. In: LOUGHLIN, Martin. WALKER, Neil (orgs). The Paradox of Constitutionalism: Constituent Power and Constitutional Form. Oxford: Oxford University Press, 2007, p. 315-338.

TUSHNET. Mark, KHOSLA, Madhav. Unstable Constitutionalism. In:TUSHNET, Mark. KHOSLA, Madhav (orgs.). Unstable Constitutionalism: Law and politics in South Asia. Cambridge: Cambridge University Press, p. 3-17.

VALE, André Rufino do. O argumento comparativo na jurisdição constitucional. Conjur. Diponível em: <https://www.conjur.com.br/2014-mai-03/observatorio-constitucional-argumento-comparativo-jurisdicao-constitucional\#_ftnref4_7296>. Acesso em: 14 fev. 2019.

VIANNA, Luiz Werneck. CARVALHO, Maria Alice Rezende de. BURGOS, Marcelo Baumann. Quem somos: a magistratura que queremos. Rio de Janeiro: Associação dos Magistrados Brasileiros, 2018.

WATERS, Melissa. Getting Beyond the Crossfire Phenomenon: A Militant Moderate's Take on the Role of Foreign Authority in Constitutional Interpretation. Fordham L. Rev., v. 77, p. 635-646, 2008. 